\title{
Type 1 reaction, neuritis and disability in leprosy. What is the current epidemiological situation?
}

\author{
C. LIENHARDT* \& P. E. M. FINE \\ Communicable Disease Epidemiology Unit, London School of \\ Hygiene and Tropical Medicine, Keppel Street, London WC1E 7 HT
}

Accepted for publication 20 September 1993

\begin{abstract}
Summary Type 1 reaction is one of the major causes of nerve damage in leprosy patients leading to disabilities of varying severity. Though this complication of leprosy has been extensively described, we still know very little of its natural history and of the factors which may predispose to it. This paper examines the descriptive and analytic epidemiology of these reactions in leprosy. We find that they vary greatly in clinical expression, time of onset, duration and severity, which has important implications for the way they are handled in the context of leprosycontrol programmes. We review the various risk factors that have been suggested over the last 30 years and the evidence of their utility in identifying 'high-risk' patients is assessed. We then review the specific aspects of neuritis and disability in leprosy and examine the contribution of Type 1 reaction to leprosy-associated disabilities. The prospects for early detection and prevention of Type 1 reaction are examined in the light of current knowledge, both at research and at the leprosy control level.
\end{abstract}

\section{Introduction}

Leprosy causes disability through damage to peripheral nerves, resulting in a loss of nerve function, which may affect seriously the future health and livelihood of leprosy patients. Nerve damage can occur across the entire spectrum of the disease, either as a chronic or as an acute phenomenon, and is sometimes responsible for real clinical emergencies. Type 1 reaction $\left(T_{1} R\right)$ is generally accepted to be one of the major causes of nerve damage in leprosy, leading to disabilities of varying severity. ${ }^{1-4}$ Though this complication has long been recognized, little is yet known of its natural history and of the risk factors which may favour it. During the 1980s much emphasis was placed on the antimycobacterial aspects of leprosy treatment, but rather less on the problem of nerve damage, though its prevention is extremely important in order to avoid permanent disability. In this regard, knowledge of the epidemiology of $T_{1} R$ and identification of potential risk factors should be of benefit to leprosy control programmes (LCP).

Two main forms of reactional states have been described, usually called Type 1 and Type 2 reactions., ${ }^{2,3}$ Type 1 reactions are characterized by episodes of increased 
inflammatory activity in skin and/or nerves of patients with borderline leprosy, whose immunological status is unstable. ${ }^{2}$ They are associated with a delayed type cellular hypersensitivity (DTH) to Mycobacterium leprae antigens. Type 2 reaction, or erythema nodosum leprosum (ENL), will not be discussed here. This reaction occurs mainly in lepromatous leprosy, usually after more than 1 year of treatment, and involves systemic symptoms. The underlying mechanism is thought to be primarily humoral, related to an Arthus phenomenon (Type II of the classification of Gell and Coombs). ${ }^{2,3}$

\section{Description}

Though Type 1 reaction is a well-known complication of leprosy, which has been discussed extensively in the literature, no agreement has yet been reached on its definition and nomenclature. ${ }^{1-3}$ There have been 2 types of $T_{1} R$ described, the so-called 'upgrading' and 'downgrading' reactions., ${ }^{2,3}$ 'Upgrading' reactions are associated with a rapid increase in the cell-mediated immune (CMI) response to $M$. leprae antigens and a decrease in bacterial load, and are interpreted as a shift across the leprosy spectrum towards the tuberculoid end. Conversely, 'downgrading' reactions are thought to be related to a partial loss of cellular immunity and a shift towards the lepromatous pole, though this is still disputed by some authors. ${ }^{6}$ In fact, the signs and symptoms accompanying upgrading and downgrading reactions are often clinically similar and may even be undistinguishable. ${ }^{7}$ Furthermore, the term 'reversal' has been used either as a synonym of $T_{1} R$ or to designate the 'upgrading' form of $T_{1} R$. In this review, the term $T_{1} R$ is used to include both upgrading and downgrading forms.

Clinically, $T_{1} R$ is characterized by episodes of increased inflammatory activity in skin lesions and/or nerves. ${ }^{7,8}$ Skin lesions become swollen and flare up. New lesions may develop. In addition, oedema may occur in the face, the hands or the feet. Inflammation in the nerves causes pain and functional impairment, which can lead to various degrees of disability, such as facial paralysis, claw hand, foot drop or anaesthesia. The nerves most at risk are the ulnar, the facial and the common peroneal nerves. ${ }^{9}$ It is widely agreed that the gravity of $T_{1} R$ is related to the degree of nerve involvement. ${ }^{10}$ Neuritis can present in different ways: it may sometimes be dramatically acute, constituting a medical emergency, ${ }^{11}$ or it may be insidious and painless ('silent neuritis'), ${ }^{12}$ leading to disability without prodromes ('quiet nerve paralysis'). ${ }^{13}$ In the latter situation, changes in sensory or motor function are not readily apparent and can be detected only by repeated nerve function assessments (sensory and motor testing).

Histologically, features of $T_{1} R$ vary according to the underlying leprosy type and the severity of the reaction. Ridley and Radia described four stages. ${ }^{14}$ In brief, the main feature of $T_{1} R$ is an influx of mononuclear cells associated with an oedema, leading to a distortion of the surrounding tissues and to compression of nerves. At a later stage, host cells change to an epithelioid form and there is formation of giant cells. The final stage is characterized by fibrosis.

Immunologically, $T_{1} R$ is associated with an increase in the CMI response to mycobacterial antigens. This was shown experimentally by Rees \& Weddel, ${ }^{15}$ who succeeded in producing $T_{1} R$ in thymectomized irradiated lepromatous mice, 1 to 2 weeks after a transfusion of syngenic lymphocytes. Godal ${ }^{5}$ confirmed these findings in human patients by demonstrating an increase in lymphocyte transformation test (LTT) response 
to whole $M$. leprae antigens during $\mathrm{T}_{1} \mathrm{R}$. Later, Barnetson et al., ${ }^{16}$ using whole and sonicated $M$. leprae as antigens for LTT, found that nerve and skin reactions in borderline leprosy patients are associated with responses to different antigens. Though these findings await confirmation, it has been suggested that in reactions involving nerves, cytoplasmic antigens are released which have previously been hidden within Schwann cells, while in reactions involving skin, there is an equivalent release of surface antigens from macrophages. Several investigators have tried to determine the various T-cell subsets involved in $T_{1} R$. It has been shown that a redistribution of the suppressor/cytotoxic subgroups occurs during $T_{1} R$, with a rise in the $T_{C D 4+} / T_{C D 8}$ ratio. ${ }^{17}$ Interferon gamma $(\mathrm{INF}-\gamma)$ produced by the $\mathrm{CD} 4+$ cells has been shown to have some role in upgrading reactions through recruitment of monocytes and activation of macrophages. ${ }^{18}$ Recently it has been reported that anti-PGL-1 IgM seropositivity was associated significantly with subsequent manifestation of $T_{1} R$ among 41 borderline leprosy patients in Nepal. ${ }^{19}$

\section{The epidemiology of $T_{1} R$}

Knowledge of the natural history of $T_{1} R$ is limited, because not many appropriate epidemiological studies have been carried out. A major problem has been the difficulty of achieving a consistent and commonly agreed case-definition of $T_{1} R{ }^{1-3,6-9}$ In fact, most authors give a clinical and/or histological description of $T_{1} R$ but few of them have given a clear case-definition. According to Ridley, ${ }^{2}$ a reaction is usually defined as an acute episode occurring in the otherwise chronic course of the infection, which appears to have an allergic basis. He further stated that downgrading and upgrading reactions were associated with a change in CMI. Later, Waters et al. ${ }^{3}$

given to the "episodes of significant inflammation occurring in leprosy which are the result of infection with $M$. leprae and are not due to secondary infection, trauma, etc. Casedefinitions used in various studies differ according to the type of clinical signs and symptoms considered (whether dermatological or neurological), their relative importance and the means of diagnosis (Table 1). This variation can be explained by the absence of any 'gold standard' for the definitive diagnosis of $T_{1} R$. In addition, as has been reported by several authors, it can be very difficult to distinguish between relapse in paucibacillary patients and late $T_{1} R$ on clinical and histological grounds. ${ }^{20-22}$ For all these reasons, it is difficult to provide accurate estimates of $T_{1} R$ incidence.

Several factors must be considered in evaluating the frequency of $T_{1} R$ : the method of case-ascertainment (hospital or population-based leprosy control programme), the type of study (retrospective, prospective or cross-sectional), the type of treatment (dapsone monotherapy, multi-drug therapy), the duration of follow-up and the geographic area (Table 2). Major referral centres generally report higher frequency of $T_{1} R$ than do leprosy control programmes, and most retrospective data accumulated over many years give general figures which do not take into account the variations in recruitment, diagnosis and treatment.

There are very few reports on the frequency of $T_{1} R$ during the dapsone monotherapy era. Because of the length of treatment ( 5 years or more for paucibacillary patients and life-long for multibacillary patients), $T_{1}$ Rs were reported to occur either 'at registration' or 'during treatment'. For some authors, any evidence of increased activity in lesions occurring during treatment was considered a reaction, whereas after treatment it was 
Table 1. Summary of case-definitions of $T_{1} R$, used in studies giving estimates of $T_{1} R$ frequency in leprosy

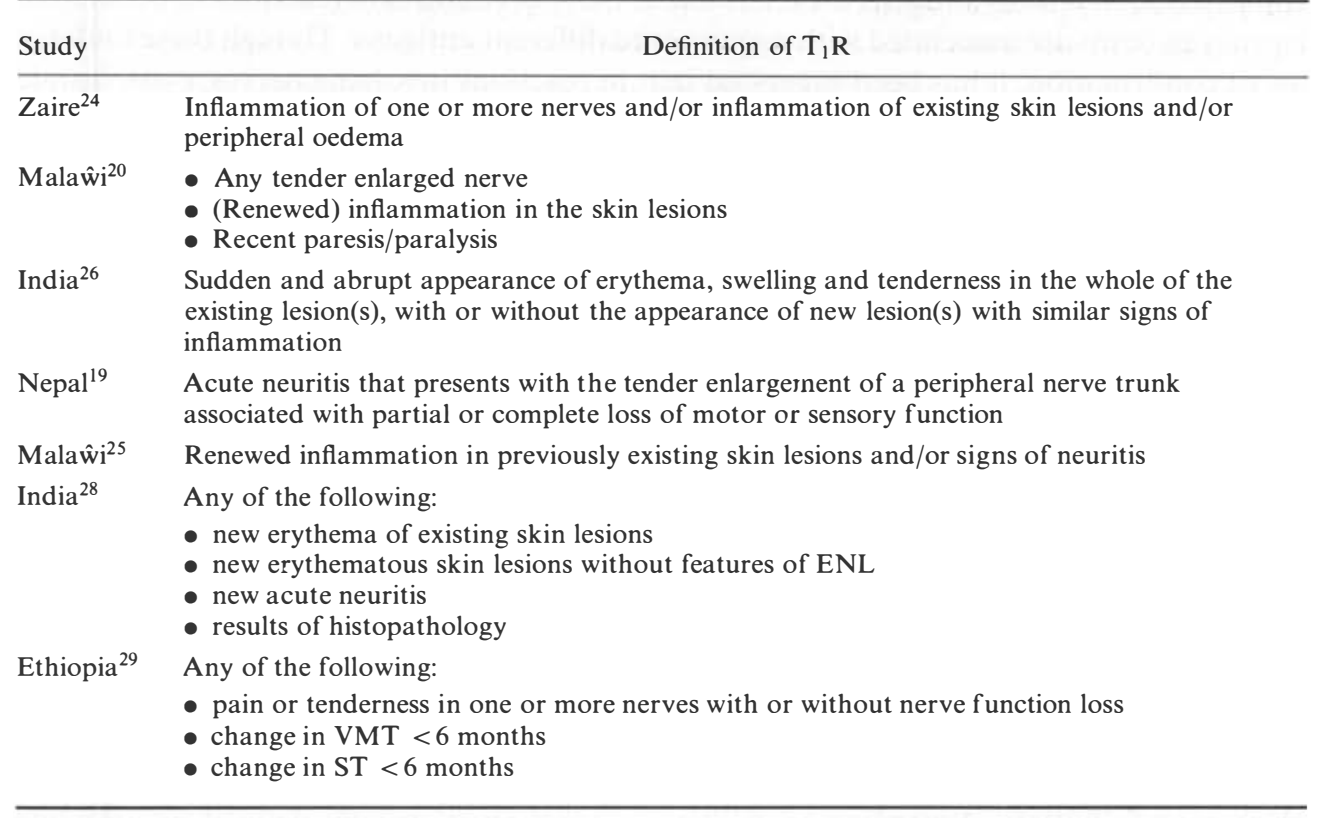

considered a relapse. In a retrospective assessment of 100 patients examined for $T_{1} R$ in 1976 in Ethiopia, it was found that 51 presented at registration with a $T_{1} R$ and one-third developed a $T_{1} R$ in year 1 of treatment, though the way in which the cases were selected for the study is not clear. ${ }^{23}$

One of the effects of introducing short-course multidrug therapy (MDT) in the treatment of leprosy has been that $\mathrm{T}_{1} \mathrm{Rs}$ now commonly occur during and after completion of treatment. Thus, in a therapeutic trial of 3 different treatment regimens of various duration (including DDS, rifampicin and clofazimine) in Zaire, 20 out of $335 \mathrm{~PB}$ patients $(6 \%)$ developed an episode of $\mathrm{T}_{1} \mathrm{R}$ within 1 year after starting treatment. Among $\mathrm{MB}$ patients $\left(\mathrm{BI} \geqslant 2\right.$ at any site), 18 out of $280(6.4 \%)$ were in $\mathrm{T}_{1} \mathrm{R}$ at time of registration, and $115(41 \cdot 1 \%)$ developed a $T_{1} R$ during treatment, 16 of them after stopping rifampicin intake at 26 weeks. ${ }^{24}$ In Malawii, 503 new PB patients (BI $\leqslant 1$ at all sites) from 2 different areas (301 in central Malaŵi and 202 in the Karonga District) were recruited in a study to evaluate the WHO-MDT regimen. Among the 301 self-reporting patients recruited in the central region, $8(2 \cdot 6 \%)$ were in 'marked $\mathrm{T}_{1} \mathrm{R}^{\prime}$ ' at registration, $5(1 \cdot 7 \%)$ developed a $\mathrm{T}_{1} \mathrm{R}$ during treatment and $12(3.9 \%)$ after treatment. ${ }^{20}$ After 4 years follow-up of the whole cohort, 17 out of $499(3.5 \%)$ were reported to have developed $T_{1} R, 15$ of them within the first 12 months after completion of treatment. ${ }^{25}$ In India, among 95 PB patients treated with MDT, $9 \%$ developed $\mathrm{T}_{1} \mathrm{R}$ in year 1 after completing treatment. ${ }^{26}$ Unfortunately, the data collected from these various studies and reports are not comparable, as different classification of leprosy cases and different definitions and diagnostic criteria of $T_{1} R$ were used.

There is a general agreement among authors that $T_{1}$ Rs particularly occur in borderline (BT to BL) leprosy. ${ }^{2,3,8}$ As can be seen in published reports and studies, the risk of $T_{1} R$ appears to be a function of leprosy classification (Table 2). In Addis Ababa, of 692 
Table 2. Summary of published estimates of $T_{1} R$ frequency in leprosy

\begin{tabular}{|c|c|c|c|c|c|c|c|}
\hline \multirow[b]{2}{*}{ Study } & \multirow{2}{*}{\multicolumn{2}{|c|}{$\begin{array}{c}\text { No of } \\
\text { patients/type } \\
\text { of leprosy }\end{array}$}} & \multicolumn{3}{|c|}{ No of $T_{1} R(\%)$} & \multirow[b]{2}{*}{$\begin{array}{c}\text { Follow-up } \\
\text { duration }\end{array}$} & \multirow[b]{2}{*}{ Total } \\
\hline & & & $\begin{array}{c}\text { Before } \\
\text { treatment }\end{array}$ & $\begin{array}{c}\text { During } \\
\text { treatment }\end{array}$ & $\begin{array}{c}\text { After } \\
\text { treatment }\end{array}$ & & \\
\hline \multirow[t]{4}{*}{ Ethiopia $^{23}$} & & & & $<1$ year DDS & $>1$ year DDS & NS & \\
\hline & BT & 50 & 30 & 19 & 1 & & \\
\hline & $\mathrm{BB}$ & 13 & 9 & 3 & 1 & & \\
\hline & $\mathrm{BL}$ & 37 & 12 & 13 & 12 & & \\
\hline \multirow{2}{*}{ Zaire $^{24}$} & PB & 325 & - & 20 & $(6)$ & NS & $20(6)$ \\
\hline & MB & 280 & $18(6 \cdot 4)$ & 115 & (41) & & $133(47 \cdot 5)$ \\
\hline \multirow[t]{3}{*}{ India $^{26}$} & \multicolumn{7}{|c|}{ PB (2 regimens) } \\
\hline & reg 1 & 95 & 0 & 0 & $9(9 \cdot 5)$ & 12 months & \\
\hline & reg 2 & 95 & 0 & $7(7 \cdot 3)$ & 0 & 12 months & \\
\hline \multirow[t]{5}{*}{ Malaŵwi ${ }^{20}$} & PB & 503 & & & & & \\
\hline & - $\mathrm{LCP}^{\prime}$ & 301 & $8(2 \cdot 6)$ & $5(1 \cdot 7)$ & $12(3 \cdot 9)$ & 12 months & $25(8 \cdot 3)$ \\
\hline & - Karo & gat & & & & & \\
\hline & A & 162 & - & - & $0(0)$ & & \\
\hline & $\mathrm{S}$ & 40 & $3(7 \cdot 5)$ & $2(5)$ & $3(7 \cdot 5)$ & & $8(20 \cdot 0)$ \\
\hline \multirow[t]{2}{*}{ Malaŵîi ${ }^{25}$} & \multicolumn{7}{|c|}{ PB (LCP + Karonga) } \\
\hline & & 499 & - & - & $17(3 \cdot 5)^{\S}$ & 4 years & $17(3 \cdot 5)$ \\
\hline \multirow[t]{2}{*}{ Malaŵi ${ }^{\ddagger}$} & PB & 1013 & & $24(2 \cdot 4)$ & & NS & \\
\hline & MB & 119 & & $12(10 \cdot 1)$ & & & \\
\hline \multirow[t]{7}{*}{ India $^{28}$} & TT & 77 & & $3(3 \cdot 8)$ & & 5 years & \\
\hline & BT & 218 & & $25(11 \cdot 5)$ & & (2) & \\
\hline & $\mathrm{BB}$ & 3 & & $3(100)$ & & & \\
\hline & $\mathrm{BL}$ & 67 & & $10(14.9)$ & & & \\
\hline & LL & 123 & & $3(2 \cdot 4)$ & & & \\
\hline & Other & 6 & & - & & & \\
\hline & Total & 494 & & $44(8 \cdot 9)$ & & & \\
\hline \multirow[t]{4}{*}{ Ethiopia $^{27}$} & BT & 304 & & $60(19 \cdot 7)$ & & 1 year & \\
\hline & BL & 249 & & $105(42 \cdot 2)$ & & & \\
\hline & LL & 99 & & $10(10 \cdot 1)$ & & & \\
\hline & Total & 692 & & $175(25 \cdot 3)$ & & & \\
\hline \multirow[t]{3}{*}{ Ethiopia $^{29}$} & $\mathrm{BT}^{\|}$ & 216 & $6(2 \cdot 8)$ & $22(10 \cdot 2)$ & $17(7 \cdot 9)$ & 1 year & $45(20 \cdot 8)$ \\
\hline & $\mathrm{BL}^{\top}$ & 266 & 13 & 103 & - & & $116(43 \cdot 6)$ \\
\hline & LL & 109 & 0 & 21 & - & & $21(19 \cdot 2)$ \\
\hline
\end{tabular}

* LCP: Leprosy control programme: all self-reporting patients.

$\dagger$ Karonga district. A: actively detected; S: self-reporting.

$\ddagger$ personal communication.

$\S$ Of which 15 reactions occurred during the first 12 months after MDT.

II cohort $07 / 87-07 / 88$.

ๆ cohort 07/87-12/88.

NS-non specified. 
new patients registered in 1989, $175(25 \%)$ developed a $T_{1} R$ : 60 out of $304(19 \cdot 7 \%)$ BT leprosy cases, 105 out of $249(42 \%)$ BL and 10 out of $99(10 \cdot 1 \%)$ LL cases; ${ }^{27}$ no BB cases were identified. A retrospective assessment of all leprosy cases who attended a leprosy centre in Hyderabad, India, during 1985 found that, overall, 44 out of $494(10.9 \%)$ patients were reported to have developed $\mathrm{T}_{1} \mathrm{R}$. Estimates varied according to classification: $3 / 77(3 \cdot 8 \%)$ TT, $25 / 218(11 \cdot 4 \%)$ BT, $3 / 3(100 \cdot 0 \%)$ BB, $10 / 67(14 \cdot 8 \%)$ BL, and 3/123 $(2 \cdot 4 \%)$ LL leprosy cases. ${ }^{28}$ Due to differences in the classifications employed (either clinical, bacteriological or histopathological) and in the method of recruitment of patients (surveys, self-reporting cases, actively detected cases), data are not comparable between studies and it is difficult to estimate whether or not the risk of developing $T_{1} R$ is strictly dependant upon the histological type of leprosy.

Type 1 reactions can be diagnosed at different times in the course of leprosy: at time of leprosy diagnosis, during treatment and after completion of treatment:

1. At time of leprosy diagnosis; some patients who were never before diagnosed or treated may present to LCPs for the first time in a stage of reaction. In Hyderabad, among the 44 cases of $T_{1} R$ diagnosed during 1 year, $21(47 \cdot 5 \%)$ were new leprosy patients presenting for the first time. ${ }^{28}$ In the clinical trial in Zaire, $18 / 280(6.4 \%)$ MB patients were diagnosed with $T_{1} R$ at their recruitment into the trial. ${ }^{24}$ In Addis Ababa, among 216 new BT patients diagnosed during 1 year, $6(2 \cdot 8 \%)$ presented with $T_{1} R$ at time of leprosy diagnosis and among $266 \mathrm{BL}$ patients who started MDT during a period of 18 months, 13 $(4.9 \%)$ were in $\mathrm{T}_{1} \mathrm{R}$ at time of leprosy diagnosis. In Malawi, 8/301 (2.6\%) self-reporting paucibacillary patients were in $T_{1} R$ at registration. As noted in Malawi, patients actively detected at the early stage of the disease and rapidly put under treatment are less likely to seek care than are patients with unknown or untreated leprosy who suffer from pain or acute neurological disorder or from an inflamed and painful patch on the skin. ${ }^{20}$ Poor and passive case-finding is likely to result in a higher number of $T_{1} R s$ at registration than is active case-finding. The percentage of cases in reaction at time of leprosy diagnosis thus reflects case-finding activities.

2. The occurrence of $\mathrm{T}_{1} \mathrm{R}$ during and after treatment varies according to the background leprosy type and to the type of treatment. It varies also with the quality of follow-up, which is likely to be closer in clinical trials and epidemiological studies than in general LCPs. Among the 44 cases diagnosed in Hyderabad in 1985, 42.5\% developed a $\mathrm{T}_{1} \mathrm{R}$ while under chemotherapy and $5 \%$ after chemotherapy. ${ }^{28}$ In the clinical trial in Zaire, the time of onset of $T_{1} R$ among $P B$ patients receiving 3 regimens of various duration ( 1 single dose, 10 weeks or 12 months duration) ranged from 16 to 32 weeks after the beginning of treatment. ${ }^{24}$ In Addis Ababa, among the 216 new BT patients diagnosed over 1 year, $22(10 \cdot 2 \%)$ developed a $T_{1} R$ during the 6 months course of MDT, and 17 $(7 \cdot 9 \%)$ within the first year after treatment. ${ }^{29}$ Similarly, among the $266 \mathrm{BL}$ patients who started MDT during a period of 18 months, 70 (26.3\%) developed $T_{1} R$ during the first year and $33(12.4 \%)$ during the second year of MDT. In Malawi, among the 499 PB patients followed-up after WHO-MDT, 14 (2.8\%) developed $\mathrm{T}_{1} \mathrm{R}$ within the first 6 months of treatment. ${ }^{25}$ These findings are consistent with the report of Rose and Waters, ${ }^{9}$ that the majority of $\mathrm{T}_{1} \mathrm{R}$ in $\mathrm{BT}$ patients develop within the first 6 months of treatment, but that some reactions may develop up to 3 years thereafter. In $B B$ leprosy, $T_{1} R$ usually starts within a few weeks or months after commencing MDT. In BL leprosy, $T_{1} R$ is said to occur within 1-12 months after starting MDT, but may also occur in the second, third or 
even the fourth year. ${ }^{9}$ I $n$ summary, the period of greatest risk of $T_{1} R$ among patients not in reaction at time of diagnosis is the first 6-12 months of treatment. The temporal distribution of $T_{1} R s$ according to leprosy classification in the sub-cited studies and reports is shown in Figure 1.

The duration of $T_{1} R$ varies with both the histological type and the treatment of leprosy, ranging from a few months (3-9) in BT patients to more than a year or even several years in BL or subpolar lepromatous patients. ${ }^{3,9}$ The situation is complicated by the possibility of recurrent episodes of $T_{1} R$, occurring particularly at the time of tailing off corticosteroid treatment. In the retrospective study carried out in Hyderabad, 14 out of the 44 patients with $T_{1} R$ developed further recurrent episodes: 7 had 1 recurrent reaction, 1 had 2, 2 had 3, 3 had 4 and 1 had $5 .{ }^{28}$ Recurrent episodes occurred up to 40 months after the initial reaction, but most occurred during the first 6 months after the initial episode. Whether these were related to reduced dosage of prednisolone or were new episodes is not clear. Such recurrent reactions pose a problem as some patients may become dependent upon steroid therapy.

\section{The search for risk factors}

In 1985, WHO identified prevention of disability as one of the three main objectives of leprosy control, in addition to treatment and rehabilitation of patients. ${ }^{21}$ In this context, given that $T_{1} R$ is thought to be responsible for much of the disability and deformity in leprosy, LCPs were encouraged to focus on early detection and treatment of $T_{1} R s$, in order to prevent nerve damage. It was then logical to try to identify the factors (whether clinical, histological or immunological) which might predict the occurrence of $T_{1} R$ in individual leprosy patients. Several risk factors have been suggested over the past 20 years, some of them well documented, but most based only on case reports (Table 3 ). Numerous studies have been carried out on the immunological and molecular aspects of $\mathrm{T}_{1} \mathrm{R}$, but no specific molecular mediator has been identified, and there is as yet no simple test allowing confident prediction of $T_{1} R$ risk in a patient newly diagnosed with leprosy. We review here the available evidence relating to specific risk factors.

\section{BCG VACCINATION}

It was long considered that the development of lepromatous disease in patients infected with $M$. leprae reflected some antigen-specific deficiency in the host's ability to mount an effective cellular response to the bacilli. Attempts were thus made to boost the immune system by injection of antigens of specific or related micro-organisms. Several authors investigated the use of BCG in the immunotherapy of lepromatous and borderline lepromatous patients - and some of them reported reactions among the recipients of the therapy. Thus, Montestruc ${ }^{30}$ and $\mathrm{Wade}^{31}$ reported episodes of acute inflammation in lesions of lepromatous and tuberculoid patients after BCG vaccination. Similarly, Floch $^{32}$ reported the occurrence of tuberculoid lesions in children 1-3 months after receiving BCG vaccination. Later, Convit et al. ${ }^{33}$ developed a vaccine against leprosy containing $6 \times 10^{8}$ heat-killed $M$. leprae together with BCG, injected intradermally in several sites. Among 531 patients with LL, BL and Mitsuda negative IL leprosy, 78 of 227 $(34 \%)$ LL patients and 52 out of $77(68 \%)$ BL patients developed a $T_{1} R$. This was 


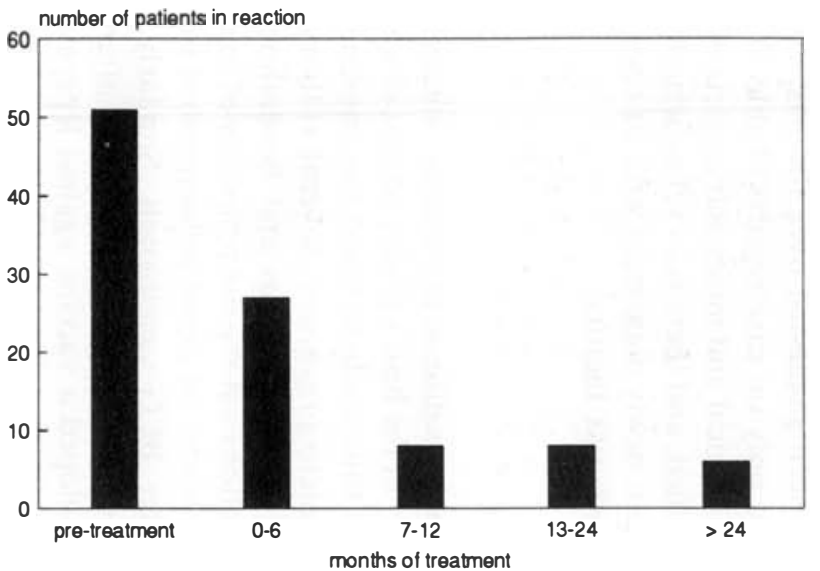

$(c)$

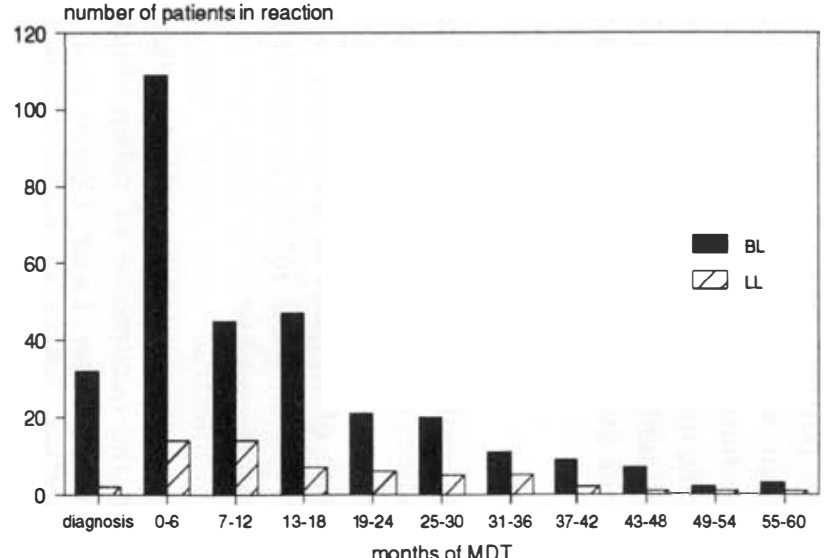

(b) number of patients in reaction

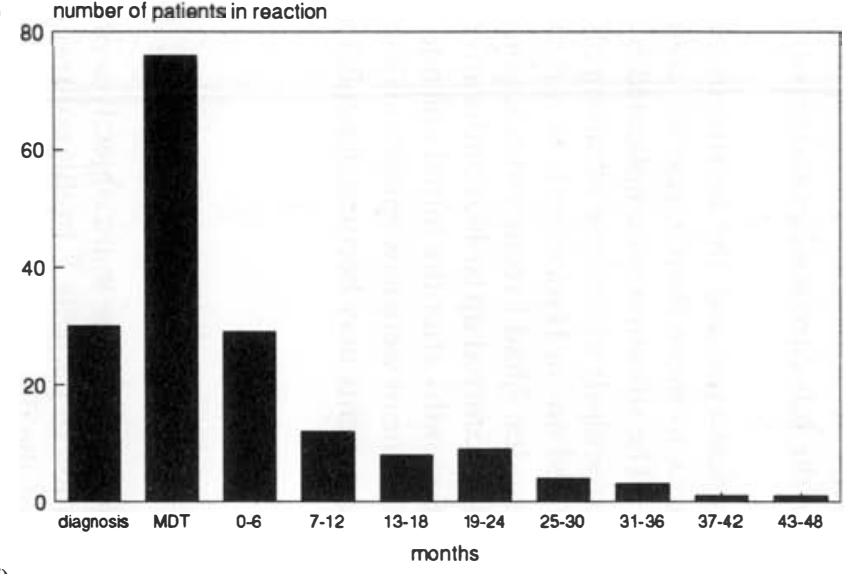

(d)

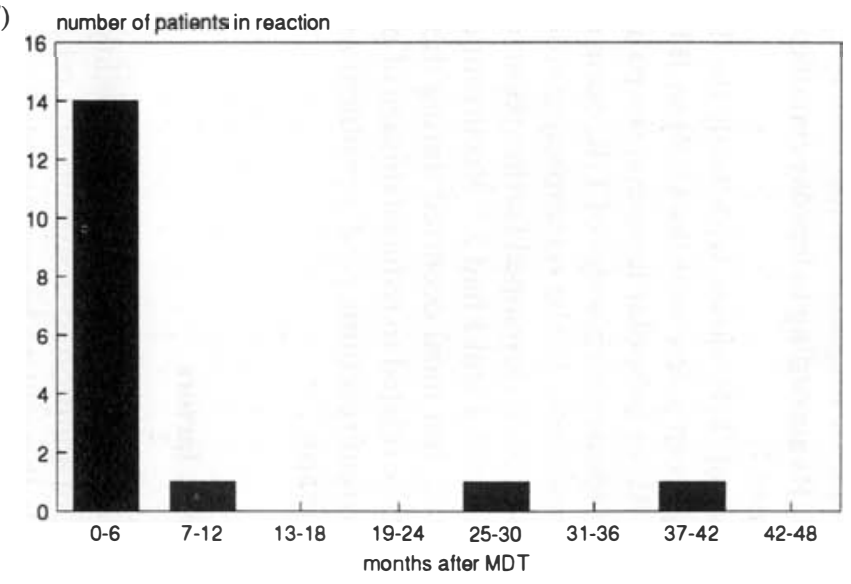

๘

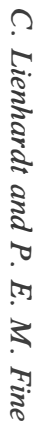

Figure 1. Temporal distribution of Type 1 reactions before, during and after treatment in various studies and reports.

(a) 100 borderline patients treated with DDS in Ethiopia; ${ }^{23}$

(b) BT patients treated with MDT between July 1987 and December 1992 in Ethiopia during and after MDT; ${ }^{29}$

(c) BL and LL patients treated with MDT between July 1987 and December 1992 in Ethiopia:;9 and

(d) Cohort of 499 patients treated with MDT followed over 4 years in Malawii. ${ }^{25}$ 
Table 3. Proposed risk factors for occurrence of $T_{1} R$ in leprosy

\begin{tabular}{|c|c|c|c|}
\hline Author & Source & Risk factor & Observation \\
\hline Floch $^{32}$ & Case-report & BCG & Tuberculoid lesions in children $1-3$ months af ter $B C G$ vaccination \\
\hline Montestruc ${ }^{30}$ & Case-report & BCG & Reaction in arrested lepromatous cases af ter BCG vaccination \\
\hline Wade $^{31}$ & Case-report & BCG & Reaction after BCG vaccination in patients with tuberculoid leprosy \\
\hline Lawson $^{34}$ & Textbook & Pregnancy and the puerperium & 'Acute reactive state' in women with leprosy after delivery \\
\hline Ridley $^{2}$ & Article & Treatment & $\begin{array}{l}\text { Risk of upgrading reactions in patients with borderline leprosy under } \\
\text { treatment and of downgrading reactions in untreated patients }\end{array}$ \\
\hline Jopling ${ }^{37}$ & Textbook & Treatment & $\begin{array}{l}\text { Risk of upgrading reactions in patients with borderline leprosy during } \\
\text { the first } 6 \text { months to } 1 \text { year of treatment. Downgrading reactions in } \\
\text { untreated patients }\end{array}$ \\
\hline $\operatorname{Rose}^{35}$ & Case-report & Pregnancy and lactation & $\begin{array}{l}\text { Adverse reactions in } 7 \text { women with untreated borderline leprosy } 3 \\
\text { weeks to } 4 \text { months after delivery }\end{array}$ \\
\hline Duncan $^{12}$ & Prospective study & Pregnancy & $\begin{array}{l}\text { Pregnancy is associated with first appearance of signs and symptoms of } \\
\text { leprosy and with relapse in cured patients. } \\
52 / 119 \text { women with leprosy presented } 85 \text { episodes of neuritis during } \\
\text { pregnancy and after delivery (mainly } 9-12 \text { months) }\end{array}$ \\
\hline Hastings $^{8}$ & Textbook & $\begin{array}{l}\text { - Vaccination } \\
\text { - Treatment (upgrading reactions) } \\
\text { - Tuberculosis } \\
\text { - Intercurrent inf ection } \\
\text { - Trauma } \\
\text { - Stress }\end{array}$ & \\
\hline Boerrigter $^{20}$ & Prospective study & Stage of disease at detection & $\begin{array}{l}\text { Risk of late } T_{1} R \text { is higher among self-reporting patients (with generally } \\
\text { more advanced disease) than among actively detected patients }\end{array}$ \\
\hline Bryceson $^{7}$ & Textbook & $\begin{array}{l}\text { - Pregnancy and lactation } \\
\text { - Vaccination } \\
\text { - Intercurrent inf ection } \\
\text { - Psychological stress }\end{array}$ & \\
\hline Rose \& Waters ${ }^{9}$ & Editorial & $\begin{array}{l}\text { - Pregnancy and lactation } \\
\text { - Intercurrent infection } \\
\text { - BCG } \\
\text { - Treatment (MDT) }\end{array}$ & $\begin{array}{l}\text { Pregnant women with leprosy are prone to develop } T_{1} R \text { 4-12 weeks } \\
\text { after delivery }\end{array}$ \\
\hline Roche $^{19}$ & Prospective study & Seropositivity to anti-PGL-1 IgM & $\begin{array}{l}\text { Seropositivity to anti-PGL-1 antibodies is significantly associated with } \\
\text { subsequent manif estation of } T_{1} R \text { in } 136 \text { patients with newly diagnosed } \\
\text { borderline leprosy }\end{array}$ \\
\hline
\end{tabular}


accompanied by an important reduction in the bacterial population within active lesions and was considered by the authors to demonstrate an increase in CMI. Most patients experienced the reactions during the first 6 months following immunotherapy.

\section{PREGNANCY AND THE PUERPERIUM}

Several reports indicate that pregnancy and the puerperium are associated with an increased risk of $T_{1} R$ in leprosy. ${ }^{34}$ In 1974, Rose described 7 cases of adverse reactions occurring 2 weeks to 4 months after delivery in women with borderline leprosy. ${ }^{35}$ On the basis of a report that maternal lymphocyte responses to PHA and PPD antigens were depressed during pregnancy and returned to normal at delivery or shortly afterwards, ${ }^{36}$ Rose suggested that $T_{1} R$ may have been precipitated by a return of CMI competence following pregnancy.

In a prospective study of 119 women with leprosy followed during pregnancy and for 2 subsequent years in Ethiopia, 52 women presented 85 episodes of neuritis during pregnancy and the puerperium $(0 \cdot 7$ episodes per patient $) .{ }^{12}$ In this study neuritis was classified as 'overt' (pain and/or tenderness of nerves) or 'silent' (impairment of motor and/or sensory function without nerve pain or tenderness) and was related either to $T_{1} R$, ENL or to 'deterioration of patients' leprosy status'. Data on the timing of neuritis in relation with pregnancy were not clearly presented, but it was reported that among the 45 women with BL leprosy, 21 (47\%) developed 35 episodes of neuritis, 3 during pregnancy and 14 during the first year after delivery. Among the 40 women with BT/TT leprosy, 16 $(40 \%)$ developed 24 episodes of neuritis, 6 of them during pregnancy. 'Overt' neuritis was reported to occur before delivery and during the first 12 months after post-partum, whereas silent neuritis occurred at all stages, but mainly after 6-9 months post-partum, though there was no evidence for a significant difference. The absence of obvious clinical signs alerting the patient (and the doctor) might have played a role in the late appearance of the latter form. Unfortunately, as no non-pregnant controls were followed-up, the relative risk of neuritis associated with pregnancy could not be calculated.

\section{CHEMOTHER APY}

The influence of antileprosy drugs on $T_{1} R$ risk has long been a subject of debate. For many years, chemotherapy was considered a risk factor for the 'upgrading' form of $T_{1} R$, which was thought to occur only in treated patients, whereas the 'downgrading' form was supposed to occur mainly in untreated patients. . $^{2,37,38}$ Despite several attempts to measure and compare the respective effects of various antileprosy drugs on $T_{1} R$, the situation still appears to be complex. ${ }^{24,39,40}$ It is difficult to evaluate whether the risk of $T_{1} R$ is different with MDT or with dapsone monotherapy. In addition, the impossibility of distinguishing clinically between upgrading and downgrading forms makes it difficult to assess this aspect of the effect of treatment.

The introduction of short-course MDT has had a complicating effect on the occurrence of $T_{1} R$ in that $P B$ patients on short-term regimens could experience reactions several months after treatment, thereby posing the difficult problem of differentiating between PB relapse and late $T_{1} R^{3,20,22,41}$ Unfortunately, as no proper clinical trial comparing DDS against MDT with a long-term follow-up was carried out before 
launching MDT, we lack information on the patterns of $T_{1} R$ in relation to different chemotherapy regimens. At present, it is cnly possible to address this issue with historical studies using very cautious criteria. Thus, a study in Malawi which compared patients diagnosed before 1981 and treated with dapsone monotherapy with patients diagnosed later and treated with WHO-MDT, found evidence that reactions were less frequent and occurred earlier in the MDT recipients (J. M. P. Pönnighaus \& R. Wilson, personal communication). In Ethiopia, an increase of the number of patients with $T_{1} R$ has been observed since the implementation of WHO-MDT, ${ }^{22,27}$ but this should be interpreted with caution, as those are crude numbers (not rates) and data on $T_{1} R$ during the dapsone monotherapy era were likely to be incomplete. The increase in reaction cases observed in this study might well be related to increased ascertainment in recent years.

\section{OTHER RISK FACTORS}

Several other potential risk factors have been mentioned in the literature, though without formal studies: intercurrent infection, in particular tuberculosis, ${ }^{7,8}$ stress, trauma (psychological and physical) ${ }^{8}$ and oral contraception. ${ }^{35}$ The little evidence on these associations is based more on anecdotal reports or hypotheses than on hard data.

HIV infection has been reported to cause several peripheral neuropathy syndromes, and there was some concern that HIV associated neuropathy might be confused with or exacerbate leprosy neuritis. ${ }^{42}$ There are reports that neuritis might be more severe in coinfected people ${ }^{43}$ and that 'new skin lesions and lepromin anergy' during treatment occur more frequently in HIV-positive than in HIV-negative leprosy patients, ${ }^{44}$ but these reports appear to be poorly documented or poorly controlled and await further investigation.

Some authors have tried to identify simple clinical factors which could allow prediction of $T_{1} R$ in patients with leprosy. In a retrospective study of 1226 PB leprosy patients, Hogeweg et al. ${ }^{45}$ identified $26(2 \cdot 1 \%)$ patients with lagophthalmos-24 had signs and symptoms compatible with $\mathrm{T}_{1} \mathrm{R}$ and among those 22 had a patch of more than $3 \mathrm{~cm}$ around the eye or the malar region. The authors concluded that facial nerve damage was more likely to occur in patients developing $T_{1} R$ with an inflamed patch on the face. Unfortunately, the chronology of events in these patients is not clear and, as no appropriate controls were identified, no relative risk could be calculated.

The mode of detection plays an important role in the reported frequency of $T_{1} R$ in leprosy. In a follow-up study of PB patients treated with WHO-MDT in 2 different areas in Malawi, Boerrigter et al. found that the risk of $T_{1} R$ during the year after registration was higher among self-reporting than among actively detected patients. ${ }^{20}$ Self-reported patients were also found to be more likely to have palpable enlarged nerves at intake than were the actively detected patients.

The quest for risk factors includes the identification of biological markers which could allow anticipation of $T_{1} R$ in patients with leprosy. In a prospective study of 136 borderline leprosy patients treated with MDT in Nepal, Roche et al. ${ }^{19}$ found that seropositivity to anti-PGL-1 antibodies, assessed with an ELISA assay, was associated significantly with subsequent manifestation of $T_{1} R$. This association was strongest in patients who were both anti-PGL-1 antibody seropositive and lepromin positive. The authors suggested that patients who are both lepromin and anti-PGL-1 positive at the time of diagnosis should be monitored closely during the first 6 months of chemotherapy 
as they are at high risk of developing $\mathrm{T}_{1} \mathrm{R}$. This study shows that it might be possible to find markers to identify persons at risk of developing $T_{1} R$, but further work is needed to clarify the relationship and to assess the respective effects of age, sex, smear positivity and leprosy classification. The question also arises of the feasibility of such tests to detect patients at risk under field conditions and whether these results could ever warrant a systematic testing of 'high-risk' leprosy patients.

\section{The impact of $T_{1} R$ in leprosy: neuritis and disability}

\section{NEURITIS: THE IMPORTANCE OF EARLY DETECTION OF NERVE DAMAGE}

$M$. leprae has the unique characteristic of entering peripheral nerves and multiplying within Schwann cells. The response of the tissue to this invasion is extremely variable: ${ }^{4}$ it can be minimal with no functional changes in the nerve or it may be very extensive, resulting in nerve destruction and complete loss of function. Literally 'inflammation of the nerves, neuritis is usually defined as 'pain and/or tenderness in the nerves' ${ }^{46}$ Neuritis and nerve damage are, however, not synonymous: there can be neuritis with little or no evidence of nerve damage and, conversely, nerve function can deteriorate in the absence of nerve pain or tenderness. ${ }^{4}$

Neuritis is the most important and serious aspect of $T_{1} R$ which, if not treated, carries the risk of irreversible disability and deformity. ${ }^{27}$ According to Pearson, ${ }^{46}$ nerve damage in $T_{1} R$ is the result of the host's immune response to the presence of antigenic material derived from the leprosy bacilli within the nerves. For Job, ${ }^{4}$ 'much of nerve destruction takes place during the reactive phases of leprosy', due to the combined effects of increased intraneural pressure caused by the inflammatory process within the nerve and extensive intraneural vascular changes.

There is great variation in clinical presentation of neuritis, from 'quiet nerve paralysis' ${ }^{13}$ or 'silent' neuritis ${ }^{12,47}$ to acute 'overt' neuritis, ${ }^{12}$ with apparently similar risk of disability, but the respective importance of motor and sensory dysfunction may vary according to the type of nerve involved. Little is known of the distribution and outcome of these different forms. In the study of neuritis in pregnant women in Ethiopia, among the 85 episodes of neuritis occurring during pregnancy or lactation, 74 episodes were followed by persistent nerve damage: 29 showed motor loss only, 12 sensory loss only, and 33 developed mixed motor and sensory loss. ${ }^{12}$ Silent neuritis appeared to occur more frequently than overt neuritis and to cause more damage to sensory nerves than to motor nerves, though the difference was not statistically significant.

It is generally reported that nerve damage can be reversed if treatment is given early enough, e.g. within 6 months of onset. ${ }^{27}$ It is therefore important in leprosy control programmes to detect signs of neuritis (either overt or silent) early in order to increase the chances of recovery and to prevent disability. Patients with overt neuritis usually report to clinics because of obvious symptoms (pain, tenderness or acute function loss), but the main problem lies in patients who slowly develop a progressive function loss without any patent signs of neuritis, i.e. 'silent neuritis'. ${ }^{12,13}$ In this situation, nerve damage can be detected only by repeated testing of nerve function.

The signs and symptoms of neuritis include pain, tenderness and nerve enlargement. Their assessment is, however, subjective and liable to variation, and the ability of such 
assessments to measure changes in nerve function over time is limited. Several tests have been developed to grade and monitor motor and sensory function:

\section{Motor function}

Goodwin ${ }^{48}$ developed in 1968 a voluntary motor test (VMT) for leprosy patients, based on the MRC scale of strength. ${ }^{49}$ This test was subsequently reviewed by several authors. ${ }^{50-52}$ While there is a general agreement on the type of muscles to be tested, several scales have been proposed to grade the muscular strength. The most frequently used is the MRC scale, which grades muscular strength on a 5-point scale, but simpler 3- or 4-point scales have also been devised, mainly for field use ${ }^{53}$ (Appendix 1).

\section{Sensory function}

Various methods have been developed to test the different aspects of sensory function. ${ }^{52}$ The most commonly used are those based on nylon monofilaments ${ }^{54-56}$ or on a ball-point pen. ${ }^{57}$ The 2 methods are not strictly comparable because the nylon filaments test the sensory response to an increasing range of determined forces, whereas the ball pen tests the response to a single stimulus. Though the latter method is less standardized, many authors prefer to use it, especially in the field, because of its simplicity and low cost, in contrast to the nylon monofilaments which are more complicated to use and more expensive.

In order to follow accurately the evolution of a patient during or after chemotherapy, and to enable an early detection of nerve function loss (especially in the absence of visible clinical signs), tests have to be repeated regularly. The need for continued monitoring of nerve function implies the use of a repeatable and reliable test. Variability between observers must be kept to a minimum in order to allow comparability of the results when tests are performed by different observers. ${ }^{58}$ This implies careful training and ongoing supervision of leprosy workers involved in nerve examination. Studies are still needed to evaluate the repeatability of these tests and to assess intra- and inter-observer variation, in order to identify which tests are the most practical and least liable to variation when used on successive measurements.

\section{DISABILITY IN LEPROSY AND ITS ASSOCIATION WITH $\mathrm{T}_{1} \mathrm{R}$}

The public health importance of leprosy is a function of the disabilities associated with the disease. Most leprosy disability follows damage to peripheral nerves and is a consequence of anaesthesia, dryness of skin and/or muscular paralysis, in various combinations. ${ }^{7}$ The importance of disabilities in the control of leprosy from the human, social and economic point of view was recognized long ago. ${ }^{59}$ Despite this, few studies have tried to measure the risk of disability in patients with leprosy and the burden of disability attributable to leprosy in general populations, let alone the relationship between $T_{1} R$ and disability in leprosy.

Most of the published estimates of disability related to leprosy are prevalence figures (percentages of leprosy cases with disability, sometimes called 'disability rates'), but the definitions of disability and the criteria used for classification are often unclear (Table 4). 
Table 4. Definition, classification and estimates of disability frequency in various studies (see text)

\begin{tabular}{|c|c|c|c|c|c|}
\hline Author & Type of study & $\begin{array}{l}\text { Definition } \\
\text { of disability }\end{array}$ & $\begin{array}{l}\text { Classification } \\
\text { of disability }\end{array}$ & $\begin{array}{l}\text { Frequency estimates } \\
\text { of disability }\end{array}$ & Comments \\
\hline Martinez-Dominguez $^{59}$ & Population surveys & No & WHO scale $(1960)^{60}$ & $\begin{array}{l}\text { Nigeria: } 23 \cdot 4 \% \\
\text { Cameroon: } 37 \cdot 6 \% \\
\text { Thailand: } 41 \cdot 5 \%\end{array}$ & $\begin{array}{l}\text { - \% dis. higher in males } v \text { females } \\
\text { - \% dis. increases with age } \\
\text { - \% dis. higher in lepromatous } v s \\
\text { nonlepromatous group }\end{array}$ \\
\hline Srinivasan \& Nordeen ${ }^{61}$ & Population survey (males $>15$ ) & No & $\begin{array}{l}\text { Social/physical } \\
\text { def ormity scale }\end{array}$ & $\begin{array}{l}165 / 465=33 \cdot 5 \% \\
\text { (all disabilities) }\end{array}$ & $\begin{array}{l}-\% \text { dis. increase with age and } \\
\text { duration of disease } \\
-\% \text { dis. higher in lepromatous } v s \\
\text { nonlepromatous group }\end{array}$ \\
\hline Smith $^{62}$ & General population survey & No & $\begin{array}{l}\text { Disability Index } \\
\left(\text { DI-2) }{ }^{63}\right.\end{array}$ & $292 / 931=31 \%$ & $\begin{array}{l}\text { —\% dis. higher in males } v \text { f females } \\
\text { — } \% \text { dis. increases with age } \\
\text { — } \% \text { dis. varies with type of leprosy }\end{array}$ \\
\hline Reddy $^{64}$ & Population survey (6 villages) & No & $\begin{array}{l}\text { Disability Index } \\
\text { (DI-2) } \\
\text { WHO scale }(1970)^{68}\end{array}$ & $31 / 191=16 \cdot 2 \%$ & $\begin{array}{l}\text { —\% dis. higher in males } v \text { s females } \\
-\% \text { dis. increases with age } \\
-\% \text { dis. higher in agricult than } \\
\text { students }\end{array}$ \\
\hline Sehgal ${ }^{65}$ & $\begin{array}{l}\text { Retrospective assessment } \\
\text { (patients seen in an urban } \\
\text { leprosy centre) }\end{array}$ & $\begin{array}{l}\text { No. Both } \\
\text { deformity/ } \\
\text { disability } \\
\text { used }\end{array}$ & $\begin{array}{l}\text { WHO scale }(1960)^{60} \\
\text { VMT, ST }\end{array}$ & $105 / 350=30 \%$ & $\begin{array}{l}\text { — } \% \text { dis. higher in males } v s \text { females } \\
\text { - } \% \text { dis. higher in young vs old age } \\
\text { group } \\
-\% \text { dis. higher in PB } v s \mathrm{MB} \text { and } \\
\text { develop earlier }\end{array}$ \\
\hline Keeler $^{66}$ & Retrospective assessment & No & No & $2 / 335=0 \cdot 6 \%$ & $\begin{array}{l}29 \% \text { patients lost to follow-up, } \\
\text { migrated, discharged or dead }\end{array}$ \\
\hline Pönnighaus ${ }^{67}$ & Retrospective cohort study & No & $\begin{array}{l}3 \text { groups: mild, } \\
\text { moderate, severe. } \\
\text { Correspondence } \\
\text { with WHO scales } \\
\text { given }\end{array}$ & $\begin{array}{l}\text {-during treatment: } \\
2 \cdot 9 / 1000 \mathrm{py} \\
\text {-after treatment: } \\
8 \cdot 0 / 1000 \mathrm{py}\end{array}$ & $\begin{array}{l}\text { - } \% \text { dis. at registration increases with } \\
\text { age } \\
\text {-DR higher in males than females } \\
\text {-DR higher in passively } v \text { s actively } \\
\text { detected patients } \\
\text { - DR higher af ter than during } \\
\text { treatment }\end{array}$ \\
\hline
\end{tabular}


Some of the reports come from leprosy institutions or hospitals where patients are highly selected and do not reflect the situation in the general population. When measured in population surveys, the estimates give only a global picture of disability in leprosy populations, as all types of disability (old and new, mild and severe) are counted together and the time of onset of disability in relation to leprosy diagnosis and treatment is generally not taken into account.

More than 20 years ago, Martinez-Dominguez et al. carried out random population surveys of leprosy in various countries and gave estimates of percentages disabled ranging from $23.4 \%$ in Nigeria to $41 \cdot 5 \%$ in Thailand, ${ }^{59}$ using the WHO scale for grading physical disabilities resulting from leprosy. ${ }^{60}$ In a cross-sectional population survey in South India, Srinivasan \& Nordeen ${ }^{61}$ found 165 out of 465 male leprosy patients (35.5\%) with a 'disability of some kind', either physical, social or combined. Disability was not clearly defined, but the authors set up a scale to grade each particular deformity of the hands and feet. In all these studies, the proportion of leprosy patients with disability was shown to increase with age, duration of disease and treatment, and was higher towards the lepromatous end of the spectrum. In another population survey in South India, 292 out of 931 leprosy cases ( $31 \%$ ) were found disabled, ${ }^{62}$ using a Disability Index based on the 1960 WHO scale, ${ }^{63}$ but no further information on the severity of disabilities was given. Other studies using population surveys or retrospective assessment methods found disability rates between $16 \%$ and $30 \%{ }^{64,65}$ A retrospective assessment of 473 leprosy patients presenting without disability at time of diagnosis between 1971 and 1976 in Trinidad and Tobago, reported an incidence of disability after starting chemotherapy of $0 \cdot 6 \%(2 / 473)$, but almost a third of these patients (138) could not be re-examined in 1978, due to migration, lost to follow-up, discharge or death. ${ }^{66}$

Some authors have tried to estimate the risk of disability in leprosy populations using retrospective cohort studies. In Malaŵi, Pönnighaus et al. reviewed data from 1654 confirmed leprosy patients examined between 1973 and 1987 in the Karonga district. ${ }^{67}$ They graded disability of face, hands and feet together as minor, moderate and severe, to form a general disability score for each patient. They found that the proportion of leprosy patients with disability increased with age at registration. The disability rate was higher in males than in females and in self-reported compared to actively detected patients. Calculating the incidence rate of disability within this population, the authors found that the risk of acquiring a new disability in leprosy patients with no disability at registration was higher af ter treatment ( $8 / 1000$ person years) than during treatment $(2 \cdot 9 / 1000$ person years, $p<0.02$ ).

In their study in 1966 , Srinivasan $\&$ Nordeen $^{61}$ raised the possibility that 'DDS given under field conditions' might be associated with disability in leprosy populations. Subsequently, Radhakrishna and Nair, ${ }^{68}$ in a retrospective study of 5746 leprosy patients without deformity at registration and treated with dapsone, found that the incidence of deformity over a 5-year period increased significantly with regularity of drug collection. In a linked case-control study, they found that mean regularity of drug collection in deformed patients before the development of any deformity was significantly higher than the mean regularity in matched controls (leprosy patients without deformity). They concluded that a causal link between regularity of dapsone collection and the development of deformity could exist. Unfortunately, there was no definition or classification of 'deformity' in this study, and we do not know if this term includes only the physical alterations (claw hands, foot-drop, etc.) or if it includes also the common 
physiological damages of leprosy (alteration of sensory and/or motor function). Furthermore, the gravity of the deformities was not specified and we do not have any information on the $30 \%$ defaulters, which casts some doubt on case-selection and ascertainment: those patients might have defaulted due to a severe disability, whereas patients who regularly collected their drug could have done it because of mild disability. The history of reactions among patients with and without deformity was not known, and, as we have seen earlier, chemotherapy has been suggested to increase the risk of reaction in leprosy. Lastly the authors admitted that 'other' factors might be operating to lead to deformity, and they proposed further investigation on this issue.

In most studies disability or deformity are thus not clearly defined and the use of different criteria or grading scales make the estimates difficult to compare (Table 4). The wide variation in published estimates of disability in leprosy can be explained by the absence of a commonly-agreed definition of disability, the differences between the various classification systems employed and the frequent confusion between disability (alteration of function) and deformity (alteration of shape). Generally, disability and deformity are assessed using WHO scales, first proposed 30 years ago to classify disability in relation to leprosy ${ }^{60}$ and subsequently revised twice. ${ }^{69,70}$ These scales, however, do not differentiate between disability and deformity, which are assembled in the same grading system. Despite both revisions, the WHO disability scales have been subject to numerous criticisms: it has been pointed out that very significant changes can occur in the extent of disability without any change in the disability grades. ${ }^{53}$ There was also some concern that changes over time in the grades could be related to changes in method or area of testing rather than to real physical changes, as neither the method nor the testing areas were standardized. ${ }^{57}$ Several modifications of the WHO scales have been proposed, ${ }^{51,57,71}$ but there is as yet no general agreement on the definition and classification of disability.

To measure the burden of disability due to leprosy in endemic areas and to allow comparability of data, there is a need for a clear definition and a standard classification of disability. In 1980, the World Health Organization developed an International Classification of Impairment, Disability and Handicap (ICIDH), ${ }^{72}$ which gave an independent classification system for each of these 3 conditions and related the impact of illness with subsequent disorders according to the following model:

$$
\text { Disease } \rightarrow \text { Impairment } \rightarrow \text { Disability } \rightarrow \text { Handicap }
$$

Distinct definitions and classifications have been developed for each of these terms:

Impairment (I code): '[in the context of health experience], an impairment is any loss or abnormality of psychological, physiological, or anatomical structure of function'.

Disability ( $D$ code): [ . . .] a disability is any restriction or lack (resulting from impairment) of ability to perform an activity in the manner or within the range considered normal for a human being'.

Handicap (H code): '[. . .] a handicap is a disadvantage for a given individual, resulting from impairment or a disability, that limits or prevents the fulfilment of a role that is normal (depending on age, sex, and social and cultural factors) for that individual'.

One of the advantages of this classification is that it offers a progressive gradation of the disorders which may arise as a consequence of illness: impairment represents disturbance at the organ level (thus including deformity), disability represents distur- 
bance at the level of the person (limit in function or ability) and handicap reflects the individual's interaction with and his adaptation to the environment. These definitions avoid the confusion between disability and deformity ${ }^{73}$ and allow differentiation between what is observable by the physician and what is experienced by the patient. Some authors have started to examine their potential application to leprosy. ${ }^{73,74}$

Theoretically, the use of a standard classification of disability (such as the ICIDH) should facilitate the measurement of the prevalence of disability in leprosy populations and comparisons between data from different areas. It should also be possible to estimate in general populations the proportion of disability related to leprosy in comparison to that attributable to other diseases, e.g. trauma, diabetes, tropical neuropathies, for various degrees of severity. One of the difficulties in such studies will be that of differentiating between 'new' and 'old' disabilities, if the time of onset of disability in relation to leprosy diagnosis and treatment is not taken into account.

The part of disability experienced by a population which is directly attributable to leprosy might be expressed in terms of a 'population attributable risk \%' (PAR\%) or 'population attributable fraction', ${ }^{75}$ which in theory measures the reduction in disabilities which could be achieved at population level if adequate measures were taken to prevent the disabilities attributable to leprosy. The PAR \% can be calculated in 2 ways: either by measuring the risk of disability in a leprosy endemic population $\left(r_{t}\right)$ and the risk of disability in leprosy-free population $\left(r_{\mathrm{o}}\right)$, or else by measuring the prevalence of leprosy in a leprosy-endemic area $(p)$, the risk of disability among leprosy patients $\left(r_{\mathrm{i}}\right)$ and the risk of disability in comparable individuals without leprosy $\left(r_{\mathrm{o}}\right)$ :

$$
\mathrm{PAR} \%=\left(r_{\mathrm{t}}-r_{\mathrm{o}}\right) / r_{\mathrm{t}}=p(\mathrm{RR}-1) /[p(\mathrm{RR}-1)+1], \quad \text { where } \quad \mathrm{RR}=r_{\mathrm{i}} / r_{\mathrm{o}} .
$$

Though simple in theory, there are major obstacles to the estimation of the contribution of leprosy to disability in any population through calculation of the PAR\% statistic:

1. Types of disease-attributable disability differ greatly according to the diseases concerned: for example, at population level, leprosy is likely to be responsible for most of the claw hands, but would contribute very little to blindness, which is more likely, in developing countries, to be related to onchocerciasis, trachoma or vitamin A deficiency. Similarly, most foot-drop and claw toes would be attributable to leprosy, whereas most leg paralysis would be attributable to poliomyelitis or to spine traumas.

2. Disability is an insidious event in leprosy, and the time lag between the onset of leprosy and leprosy-attributable disability is extremely variable. It is therefore difficult to estimate at a given time how much of the problem could be avoided by prevention, as a substantial proportion of present leprosy-associated disabilities is probably related to leprosy which appeared several years ago, when diagnosis and treatment were different from what they are today. Consequently, the estimation of the effect of disability prevention would require follow-up lasting several years. As a contrast, contribution of car accidents to disabilities could readily be calculated and used to plan and assess a disability prevention programme, because of the short time span between such accidents and consequent disabilities.

3. The risk of disability in individuals with and without leprosy might in theory be estimated using a cohort study design, but the follow-up of such a cohort would be long and the study difficult to undertake. Another approach to the problem would be to use a 
case-control study design, in which the cases are disabled individuals, the controls are non-disabled individuals and the exposure leprosy, in order to estimate in general populations the relative risk (RR) of disability related to leprosy. This would reduce the problem of the long time span between leprosy and disability but, as noted above, the RR is likely to vary greatly according to the type of disability. In addition, the cause of disability will depend heavily on the method of recruitment of cases, especially in countries where leprosy control is still run vertically (as traumas and diabetes, for instance, will be overrepresented in public hospitals, and disabled leprosy patients will be found mainly in leprosy rehabilitation centres).

The contribution of leprosy to the disability load in general populations is thus difficult to measure and may not be readily interpretable. The same logic can, however, be applied to estimate, within leprosy patient populations, the proportion of leprosy-related disabilities attributable to $T_{1} R$, which could thus be avoided by preventing $T_{1} R$ in this population. We can illustrate the method with the data collected in Malawi by Boerrigter et al. ${ }^{25}$ who followed 503 PB leprosy patients during and after WHO-MDT. Among 499 patients followed up for 4 years, 17 developed an episode of $T_{1} R$. The risk of developing new disabilities was significantly higher among patients who experienced a severe $T_{1} R$ after completion of MDT than among those who did not $(\mathrm{RR}=19 \cdot 33, p<0.003)$. Assuming that $p$ (proportion of cases with history of reaction in the population) is equal to $17 / 499(=0 \cdot 035)$, and using the above formula, the percentage of disability due to $T_{1} R$ in leprosy in this population (PAR\%) can be estimated as $38 \%$. In other words, in this population of $\mathrm{PB}$ leprosy cases, more than a third of the leprosy-related disabilities which occurred within the 4 years after completion of WHO-MDT was attributable to $\mathrm{T}_{1} \mathrm{R}$ and could have been avoided if $T_{1} R$ were totally prevented. Further useful information on this issue could be obtained by estimating the PAR \% of disability due to $T_{1} R$ according to age, sex, leprosy type and treatment. This information could be obtained using casecontrol studies in areas where criteria used for the diagnosis of $T_{1} R$, the classification of disabilities and the chronology of events have been carefully recorded. A potential difficulty is that of attributing disability to $T_{1} R$, particularly in patients who experienced several episodes of $T_{1} R$ or other complications of leprosy, including ENL. With clear definitions and diagnostic criteria, the respective influence of $T_{1} R$ (whether single or recurrent), of ENL, or of neuritis (carefully defined) on disability in leprosy could be estimated using either cohort or case-control studies, keeping in mind the limitations of these methods. This would allow estimation of the risk of $T_{1} R$ in leprosy, and would allow calculation of the burden of disabilities attributable to reactions in a leprosy patient population. In addition, such studies would help to determine the risk factors for $T_{1} R$ and would give useful information on the pathogenesis of neuritis in leprosy.

\section{Conclusion}

Data accumulated over the past 20 years show that Type 1 reactions vary greatly in terms of clinical expression, time of occurrence, duration and consequences. This variation reflects the instability of the immune response to $M$. leprae antigens in patients with borderline leprosy. Because of this variation, it is important to base studies upon strictly defined case-definitions and diagnostic criteria.

The public health impact of leprosy is related to disabilities, which are themselves a multi-factorial consequence of nerve damage. Though nerve damage has been described by Job as an 'ever-present serious complication of all forms of leprosy', ${ }^{4}$ the relations 
between nerve damage, neuritis, $T_{1} R$ and disability are still not clear. The relationship of neuritis to Type 1 or Type 2 reaction is in particular need of clarification, as appropriate treatments are different. It is in this context that a sound knowledge of $T_{1} R$ in leprosy (definition, pathogenesis, diagnosis) is necessary, in order to evaluate its impact on disability. As discussed above, the contribution of $T_{1} R$ to the overall disability burden can in theory be estimated through the calculation of PAR\% statistics. This type of information as well as information on incidence, time of onset, duration and risk factors can most accurately be obtained through a cohort study. However, given the long duration of follow-up required to collect appropriate data on nerve damage and on disability and the trends in leprosy incidence today (which is decreasing almost everywhere in the world) ${ }^{76}$ the feasibility of cohort study designs is questionable. Alternative methods, such as case-control studies, should thus be considered, bearing in mind their constraints and limitations.

In most leprosy-control programmes, the problem of $T_{1} R$ is considered at the level of its consequences in terms of nerve damage and disability. The emphasis is on early detection of nerve damage by regular testing of nerve function during and after leprosy treatment-a mandatory complement of MDT. This approach should be feasible everywhere, provided that leprosy workers have been properly trained to perform these tests and are regularly supervised. Early detection of nerve damage is dependant upon the frequency with which tests are performed, which is a function of the number of contacts between the patients and the leprosy-control programme. This poses the problem of logistic constraints in remote areas, and emphasizes the need to ensure good patient compliance.

Another perspective at LCP level is that of predicting the occurrence of $T_{1} R$ in patients with leprosy at the time of diagnosis and during treatment, through the identification of specific risk factors. Though several risk factors have been recognized and proposed over the last 20 years, mainly based on repeated observations and reports, no controlled studies have been carried out and we still lack the means to predict reactions confidently enough to prevent them. Further studies on the epidemiology and risk factors associated with $\mathrm{T}_{1} \mathrm{R}$ in leprosy would provide a better knowledge of the natural history, predictability and preventability of this phenomenon.

With the recent WHO commitment to eliminate leprosy 'as a public health problem by the year $2000,{ }^{77}$ there are strong arguments to plan for the integration of leprosy control into general health services and/or combined programmes. ${ }^{78}$ In this context, MDT delivery becomes the responsibility of general health care workers, who will be in charge of the follow-up of patients and will thus be responsible for prevention of disability. These general health care workers will need to be trained in all aspects of leprosy control, including detection of neuritis and assessment of nerve damage, emphasizing that treatment of leprosy entails more than MDT alone. ${ }^{79}$ At the same time, the integration of leprosy into general health services will lead to an appreciation of leprosy as just one of many causes of impairment, disability and handicap in these populations. ${ }^{80}$

\section{Acknowledgments}

The authors are grateful to Dr M. Waters for his helpful comments, and to the British Leprosy Relief Organization (LEPRA) and the International Federation of Anti-Leprosy Associations (ILEP) for their financial support. 


\section{References}

1 Jopling WH. Lepr Rev, 1959; 30: 194-96.

2 Ridley DS. Reactions in leprosy. Lepr Rev, 1969; 40: 77-81.

3 Waters MFR, Turk JL, Wemambu SNC. Mechanisms of reactions in leprosy. Int J Lepr, 1971; 39: 417-428.

${ }^{4}$ Job CK. Nerve damage in leprosy. Int J Lepr, 1989; 57(2): 532-39.

5 Godal T, Myrvang B, Samuel DR, Ross WF, Lofgren M. Mechanism of 'reactions' in borderline tuberculoid leprosy (B.T.). Acta Path Microbiol Scand, 1973; 236(suppl.): 45-53.

${ }^{6}$ Klenerman P. Etiological factors in DTH reactions in leprosy. Int J Lepr, 1987; 55: 702-712.

7 Bryceson A, Pfaltzgraff RE. Leprosy, 3rd edition. 1990; Chruchill Livingstone, Edinburgh.

${ }^{8}$ Hastings RC. (Ed) Leprosy, 1985; Churchill Livingstone, Edinburgh.

9 Rose P, Waters MFR. Reversal reactions in leprosy and their management. Lepr Rev, 1991; 62: 113-119.

10 Pearson JMH, Ross WF. Nerve involvement in leprosy: pathology, differential diagnosis and principles of management. Lepr Rev, 1975; 46: 199-212.

11 Malin AS, Waters MFR, Shehade AS, Roberts MM. Leprosy in reaction: a medical emergency. BMJ, 1991; 302: 1324-26.

12 Duncan ME, Pearson JMH. Neuritis in pregnancy and lactation. Int J Lepr, 1982; 50: 31-38.

13 Srinivasan H, Rao KS, Shanmvigam N. Steroid therapy in recent 'quiet nerve paralysis'. Indian J Lep, 1982; 54: 412-419.

14 Ridley DS, Radia K B. The histological cause of reactions in borderline leprosy and their outcome. Int J Lepr, 1981; 49: 383-392.

15 Rees RJW, Weddell AGM. Experimental models for studying leprosy. Ann New York Acad Sci, 1968; 154: 214-36.

16 Barnetson RS, Bjune G, Pearson JMH, Kronwall G. Antigenic heterogeneity in patients with reactions in borderline leprosy. BMJ, 1975; 4: 435-437.

17 Narayanan RB, Laal S, Sharma AK, Bhutani LK, Nath I. Differences in predominant T cell phenotypes and distribution pattern in reactional lesions of tuberculoid and lepromatous leprosy. Clin Exp Imm, 1984; 55: 623-8.

18 Nathan CF, Kaplan G, Lewis WR, Nustrat A et al. Local and system effects of intradermal recombinant interferon in patients with lepromatous leprosy. $N$ Engl J Med, 1986; 315: 6-15.

19 Roche PW, Theuvenet JM, Britton WJ. Risk-factors for $T_{1} R$ in borderline leprosy patients. Lancet, 1991; 338: $654-657$.

20 Boerrigter G, Pönnighaus JM, Fine PEM. Preliminary appraisal of a WHO-recommended multi-drug therapy regimen in paucibacillary leprosy patients in Malawi. Int J Lepr, 1988; 56: 408-417.

${ }^{21}$ World Health Organization. Epidemiology of leprosy in relation to control. Techn. Rep. Ser. No. 716. Geneva 1985.

22 Becx-Bleuminck M. Operational aspects of multidrug therapy. Int J Lepr, 1989; 57: 540-551.

23 Naafs B, Wheate HW. The time interval between the start of anti-leprosy treatment and the development of reactions in borderline patients. Lepr Rev, 1978; 49: 153-157.

24 Groenen G, Janssens L, Kayembe T, Nollet E, Coussens L, Pattyn SR. Prospective study on the relationship between intensive bactericidal therapy and leprosy reactions. Int J Lepr, 1986; 54: 236-244.

25 Boerrigter G, Pönnighaus JM, Fine PEM, Wilson RJ. Four-year follow-up of a WHO-recommended multidrug therapy regimen in paucibacillary leprosy patients in Malawi. Int J Lepr, 1991; 59: 255-261.

${ }^{26}$ Katoch K, Ramanathan U, Natrajan M, Bagga AK, Bhatia AS, Saxana RK, Ramu G. Relapses in paucibacillary patients after treatment with three short-term regimens containing rifampicin. Int J Lepr, 1989; 57: 458-464.

27 Becx-Bleuminck M, Berhe D, Mannetje W. The management of nerve damage in the leprosy control services. Lepr Rev, 1990; 61: 1-11.

28 Lockwood DJ, Vinayakumar S, Stanley JNA, McAdam KPWJ, Colston MJ. Clinical features and outcome of reversal (Type 1) reactions in Hyderabad, India. Int J Lepr, 1993; 61: 8-15.

29 Becx-Bleuminck M, Berhe D. Occurrence of reactions, their diagnosis and management in leprosy patients treated with multidrug therapy. Experience in the leprosy control programme of the All Africa Leprosy and Rehabilitation Centre (ALERT) in Ethiopia. Int J Lepr, 1992; 60: 173-184.

30 Montestruc E. Reactions in arrested cases after BCG vaccination (letter). Int J Lepr, 1960; 28: $183-184$.

31 Wade HW. BCG induced activations (Editorial). Int J Lepr, 1960; 28: 179-181.

32 Floch H, Mailloux M. Relations entre l'apparition rapide de plusieurs cas de lèpre tuberculoide et la vaccination par le BCG intradermique chez des enfants en pays d'endémicité lépreuse. Bull Soc Path Exot, 1958; 51: 353-359.

33 Convit J, Ulrich M, Aranzazu N, Castellanos PL, Pinardi ME, Reyes O. The development of a vaccination model using two microorganisms and its application in leprosy and leishmaniasis. Lepr Rev, 1986; 57(suppl. 2): $263-273$. 
34 Lawson JB, Stewart DB. Leprosy in Obstetrics and Gynaecology in the Tropics. London, Edward Arnold (Ed) 1967.

${ }^{35}$ Rose P, McDougall C. Adverse reactions following pregnancy in patients with BL leprosy. Lepr Rev, 1975; 46: $109-114$.

36 Purtillo DT, Hallgren HM, Yunis EJ. Depressed maternal lymphocyte response to phytohaemagglutinin in human pregnancy. Lancet, 1972; 1: 769-771.

37 Jopling WH. Handbook of leprosy, 1971: London; William Heinemann Medical Books Ltd.

38 Waters MFR. Treatment of reactions in leprosy. Lepr Rev, 1974; 45: 337-341.

39 Barnetson RS, Pearson JMH, Rees RJW. Evidence for prevention of borderline leprosy reaction by dapsone. Lancet, 1976; 2: 1171-1172.

40 Pfaltzgraff RE. The control of neuritis in leprosy with clofazimine. Int J Lepr, 1972; 40: 392-398.

${ }^{41}$ Pannikar V, Jesudasan K, Vijayakumaran P, Christian M. Relapse or late reversal reaction? Int J Lepr, 1989; 57: $526-28$

42 Lucas S. Human immunodeficiency virus and leprosy. Lepr Rev, 1993; 63: 97-103.

43 Vreeburg AEM. Clinical observations on leprosy patients with HIV-1 inf ection in Zambia. Lepr Rev, 1992; 63: $134-140$.

${ }^{44}$ Pean C, Pape JW, Deschamps MM, Dantreville M, Johnson WD. Natural history of M. leprae and HIV infection. 5th Int Conf AIDS, 1989; Th.B.P.70 (Abstract).

${ }^{45}$ Hogeweg M, Kiran Ku, Suneetha S. The significance of facial patches and type 1 reactions for the development of facial nerve damage in leprosy; a retrospective study among 1226 paucibacillary leprosy patients. Lepr Rev, 1991; 62: 143-149.

46 Pearson JMH, Ross WF. Nerve involvement in leprosy-pathology, differential diagnosis and principles of management. Lepr Rev, 1975; 46: 199-212.

47 Hamilton J. Deformity prevention in the field: a systematic approach. Lepr Rev, 1983; 54: $229-237$.

48 Goodwin CS. The use of voluntary muscle test in leprosy neuritis. Lepr Rev, 1968; 39: 209-216.

49 MRC: Aids to the investigation of peripheral nerve injuries. MRC Memo No. 7; London; HMSO.

50 Naafs B, Van Droegenbroeck JBA. Etude comparative d'une série de nerfs lépreux décomprimés chirurgicalement par rapport aux nerfs controlatéraux non opérés. Med Trop, 1977; 37: 763-770.

51 Brandsma W. Basic nerve function assessment in leprosy patients. Lepr Rev, 1981; 52: 161-170.

52 Pearson JMH. The evaluation of nerve damage in leprosy. Lepr Rev, 1982; 53: 119-130.

53 Watson JM. Disability control in a leprosy control programme. Lepr Rev, 1989; 60: 169-172.

54 Jamison DG. Sensitivity testing as a means of differentiating the various forms of leprosy found in Nigeria. Lepr Rev, 1969; 40: 17-20.

55 Naafs B, Dagne S. Sensory testing: a sensitive method in the follow-up of nerve involvement. Int J Lepr, 1977; 45: $364-368$.

56 Bell-Krotoski J, Tomancik E. The repeatability of testing with Semmes-Weinstein monofilaments. $J$ Hand Surg, 1987; 12: 155-161.

57 Watson JM. WHO disability grading. Letter to the Editor. Lepr Rev, 1985; 172-175.

${ }^{58}$ Lienhardt C, Currie H, Pasquier R, Wheeler J. Inter-observer variation in the assessment of nerve function in leprosy patients in Ethiopia and Nepal. 14th International Leprosy Congress, Orlando, USA, 1993. (Abstract).

59 Martinez-Dominguez V, Bechelli LM, Patwary KM. WHO surveys of disabilities in leprosy in Northern Nigeria, Cameroon and Thailand. Int J Lepr, 1966; 34: 244-254.

60 World Health Organization. Expert Committee on Leprosy. Techn Rep Ser, No. 189. Geneva 1960.

${ }^{61}$ Srinivasan H, Nordeen SK. Epidemiology of disability in leprosy. Int J Lepr, 1966; 34: 159-169.

62 Smith WCS, Antin US, Patole AR. Disability in leprosy: a relevant measurement of progress in leprosy control. Lepr Rev, 1980; 51: 155-166.

${ }^{63}$ Bechelli LM, Martinez Dominquez V. Disability Index for leprosy patients. Bull Wld Hlth Org, 1971; 44: 709712.

64 Reddy BN, Bansal RD. An epidemiological study of leprosy disability in a leprosy endemic rural population of Pondichery (South India). Ind J Lepr, 1984; 56: 191-199.

65 Sehgal VN, Sharma PK. Pattern of deformities/disabilities in urban leprosy. Ind J Le pr, 1985; 57: $183-192$.

66 Keeler RF, Ryan MA. The incidence of disabilities in Hansen Disease af ter commencing chemotherapy. Lepr Rev, 1980; 51: 149-154.

67 Pönnighaus I, Boerrigter G, Fine PEM, Pönnighaus JM, Russell J. Disabilities in leprosypatients ascertained in a total population survey in Karonga District, Northern Malaŵi. Le pr Rev, 1990; 61: 366-374.

68 Radhakrishna S, Nair NGK. Association between regularity of dapsone (DDS) treatment and development of deformity. Int J Lepr, 1987; 55: 425-34.

69 World Health Organization. Expert Committee on Leprosy. Techn Rep Ser, No. 459. Geneva 1970.

70 World Health Organization. Expert Committee on Leprosy. Techn Rep Ser, No. 768. Geneva 1988.

71 Hasan S. An appraisal of use of the classification of disabilities resulting from leprosy in field work and suggestions for improvement. Lepr India, 1982; 54: 135-143. 
72 World Health Organization. International Classification of Impairments, Disabilities and Handicaps. World Health Organization, Geneva, 1980.

${ }^{73}$ Smith WCS. The epidemiology of disability in leprosy, including risk factors. Lepr Rev, 1992; 63: 23s-30s.

${ }^{74}$ Brandsma JW, Heerkens YF, Lakervelf-Heyl K, Mischner-Van Ravenberg CD. The International Classification of Impairments, Disabilities and Handicaps in leprosy control projects. Lepr Rev, 1992; 63: 337-344.

75 Hennekens CH, Buring JE. Epidemiology in Medicine, 1st Ed. Little, Brown \& Co, 1987, Boston.

${ }^{76}$ Fine PEM. Reflections on the elimination of leprosy. Int J Lepr, 1992; 60: 71-80.

77 Nordeen SK. Elimination of leprosy as a public health problem by the year 2000. Lepr Rev, 1992; 63: 1-4.

78 Feenstra P. Leprosy control through general health services and/or combined programmes. Lepr Rev, 1993; 64: 89-93.

79 Lienhardt C, Fine PEM. Controlling leprosy: MDT is not enough alone. BMJ, 1992; 305: $206-207$.

80 World Bank. World Development Report 1993. Oxf ord University Press, New York. 


\section{APPENDIX 1}

\section{Scales used in voluntary motor testing}

1. MRC SCALE:

The examiner first demonstrates the correct movement to the patient, and then asks him to repeat it spontaneously. If the patient is able to perform the full range of the demonstrated movement, he is asked to hold it against resistance. According to the result, the examiner grades the movement as follows:

- Grade 5: Full range of movement against resistance

- Grade 4: Full range of movement but less than normal resistance

- Grade 3: Full range of movement but no resistance

- Grade 2: Partial range of movement with no resistance

- Grade 1: Perceptible contraction of the muscle not resulting in joint movement

— Grade 0: Complete paralysis

2. 'SRMP' SCALE

The same procedure applies, with the following scale:

- Strong: $\quad$ Full range of the movement against resistance

- Resistance reduced: Reduced range of the movement against resistance

- Movement reduced: Range of spontaneous movement reduced

- Paralysis: No spontaneous movement

3. 'SWP' SCALE:

As before, but with a 3-point scale:

- Strong: Full range of the movement against resistance

- Weak: Weak movement against or without resistance

- Paralysis: No spontaneous movement 


\section{APPENDIX 2}

\section{Sensory testing}

1. NYLON FILAMENTS (adapted from Bell-Krotoski 1956)

Semmes-Weinstein graded nylon monofilaments are used on specific sites of the hands and feet. Each filament is applied slowly to bending, held for 1.5 seconds and lif ted slowly while the patient's eyes are closed or otherwise averted. Each filament is applied 3 times in each tested area. Each time, the patient is asked to point out the stimulated area. If the patient points at least twice within $2 \mathrm{~cm}$ of the stimulated point, the response is judged correct for that filament. The lightest filament (number 5) is applied first. If it is felt, the number 5 is recorded in the blank corresponding to the touched area. If this is not felt, the next heavier filament is tried (number 4), and so on for the remaining filaments. If no filament is felt, a zero is placed in the blank, showing complete anaesthesia in this area.

Various nylon filaments are used for the hands and feet in leprosy centres worldwide, but the most used are:

- hands: $\quad \mathrm{g}$

Number 5: $0 \cdot 2$

Number 4: $\quad 2 \cdot 0$

Number 3: $\quad 4 \cdot 0$

Number 2: $\quad 10 \cdot 0$

Number 1: $300 \cdot 0$

- feet:

Number 3: $\quad 2 \cdot 0$

Number 2: $\quad 10 \cdot 0$

Number 1: $300 \cdot 0$

2. BALL-POINT PEN (Watson 1953)

A ball-point pen is applied on specific sites of the hands and feet, allowing a denting of 1 mm during $2 \mathrm{sec}$, while the patient's eyes are closed. He/she is asked to point the stimulated area with the finger. The ball pen is applied 3 times on each site. If the patient responds to at least 2 out of the 3 applications within $2 \mathrm{~cm}$ on a specific site, the response is correct and coded 1 , otherwise 0 . 


\title{
Réaction de Type I, névrite et infirmité dans la lèpre. Où en est la situation épidémiologique?
}

\author{
C. Lienhart et P. E. M. Fine
}

Résumé La réaction de Type I est une des principales causes de lésion nerveuse chez les lépreux entrainaut à des infirmités de gravité diverse. Bien que cette complication de la lèpre ait été largement décrite, nous connaissons encore très peu son histoire naturelle et les facteurs qui peuvent y prédisposer. Cet article examine l'épidémiologie descriptive et analytique de ces réactions dans la lèpre. Se apparaît qu'elles varient largement dans leur tableau clinique, le moment de leur apparition, leur durée et leur gravité, ce qui a des implications importantes sur la façon de les traiter dans les programmes de contrôle de la lèpre. Nous examinons les divers facteurs de risques qui ont été suggérés au cours des 30 dernières années et les preuves de l'utilité de ces facteurs pour l'identification des patients à haut risque. Nous examinons ensuite les aspects spécifiques de la névrite et de l'infirmité dans la lèpre et nous recherchons la contribution de la réaction Type I aux infirmités associées à la lèpre. Les perspectives pour le dépistage précoce et la prévention de la réaction Type I sont examinées à la lumière de nos connaissances actuelles, au niveau de la recherche et du contrôle de la lèpre.

\section{La reacción de Tipo 1, neuritis y deshabilidad en la lepra. ¿Cuál es la situación epidemiológica actual?}

\author{
C. LienhaRdT y P. E. M. Fine
}

Resumen La reacción de tipo 1 es una de las causas principales del daño causado a los nervios de los leprosos que resulta en minusvalidez de severidad variable. Aunque se ha descrito extensamente esta complicación de la lepra, se conoce muy poco de sus antecedentes naturales y de los factores que puedan acentuarlo. Esta publicación examina la epidemiología descriptiva y analítica de esta reacciones en la lepra. Establecimos que varían mucho en carácter clínico, iniciación, duración y severidad, lo que tiene implicaciones importantes sobre la manera de que se manejan en el contexto de los programas de control de la lepra. Se han evaluado los varios factores de riesgo que se han sugerido durante los últimos 30 años y las pruebas que existen para la identificación de pacientes más expuestos al riesgo. Luego estudiamos los aspectos específicos de la neuritis y la deshabilidad en la lepra y examinamos la contribución de la reacción de tipo 1 a las deshabilidades asociadas con la lepra. Se examinan las posibilidades de una detección y prevención tempranas de la reacción de tipo 1 en vista de los conocimientos actuales, tanto en las investigaciones como en el nivel del control de la lepra. 